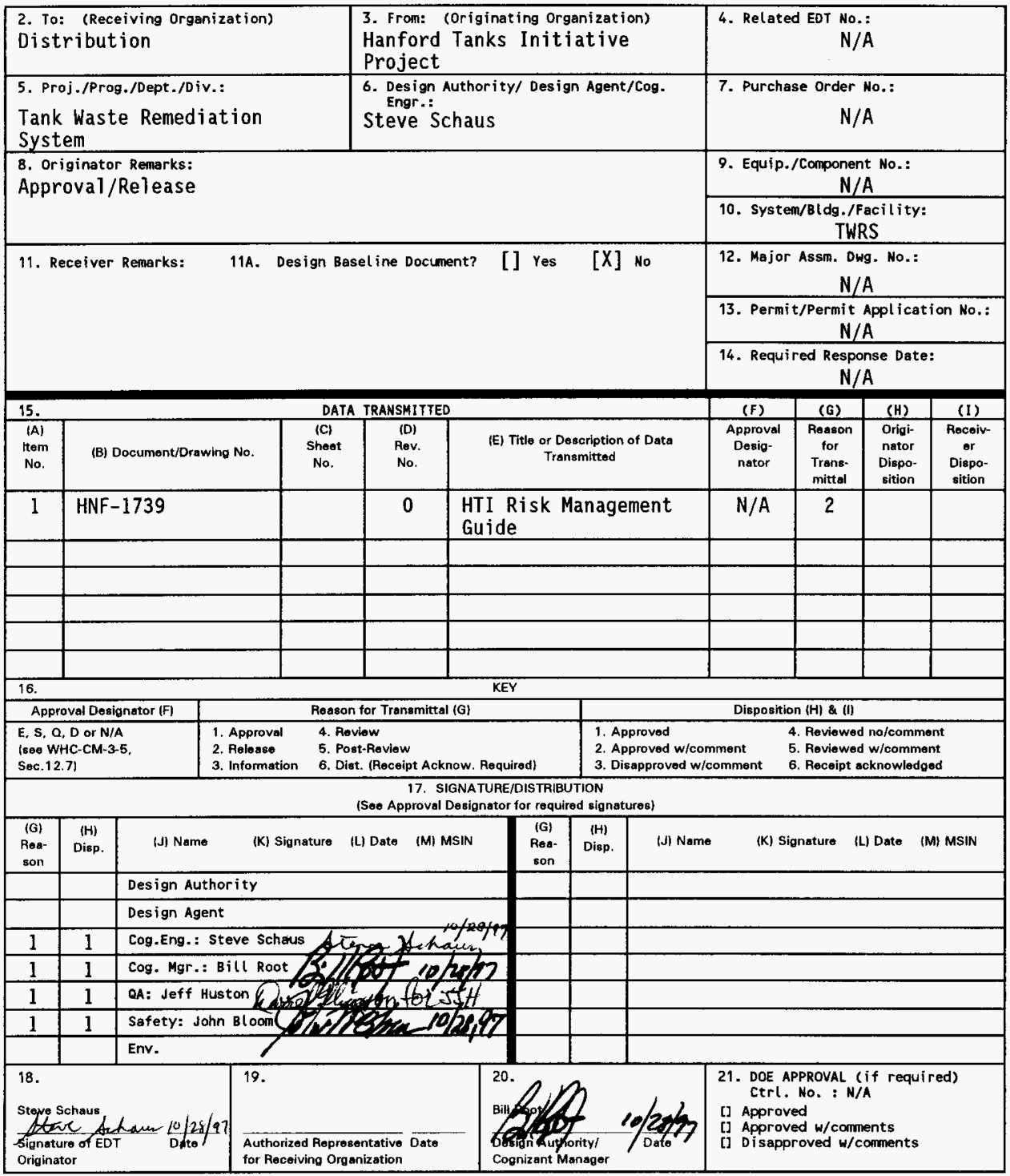




\title{
Hanford Tanks Initiative Risk Management Guide
}

\author{
Steve Schaus \\ Lockheed-Martin Hanford Company, Richland, WA 99352 \\ Jim Schaefer \\ TRW Systems Integration Group, Richland, WA 99352 \\ U.S. Department of Energy Contract DE-AC06-96RL13200
}

$\begin{array}{lll}\text { EDT/ECN: } & \text { EDT } 622809 & \text { UC: } 2030 \\ \text { Org Code: } & 73500 & \text { Charge Code: } \\ \text { B\&R Code: } & \text { EW4010000 } & \text { Total Pages: }-24,25\end{array}$

Key Words: Hanford Tanks Initiative, HTI, systems engineering, risk management, risk status, risk handling, Risk Management List

Abstract: This project-specific Risk Management Guide describes the general approach and process being used by the HTI Project to manage risk associated with execution of the HTI mission. It includes the initial identification of risk and the quantification of its likelihood and severity of its consequences. It further addresses the formulation of risk mitigation plans, periodic statusing of the Risk Management List, and risk closure.

TRADEMARK DISCLAIMER. Reference herein to any specific comercial product, process, or service by trade name, trademark, manufacturer, or otherwise, does not necessarily constitute or imply its endorsement, recommendation, or favoring by the United states Government or any agency thereof or its contractors or subcontractors.

Printed in the United States of America. To obtain copies of this document, contact: Document Control Services, P.0. Box 950, Mailstop H6-08, Richland WA 99352, Phone (509) 372-2420; Fax (509) 376.4989 .
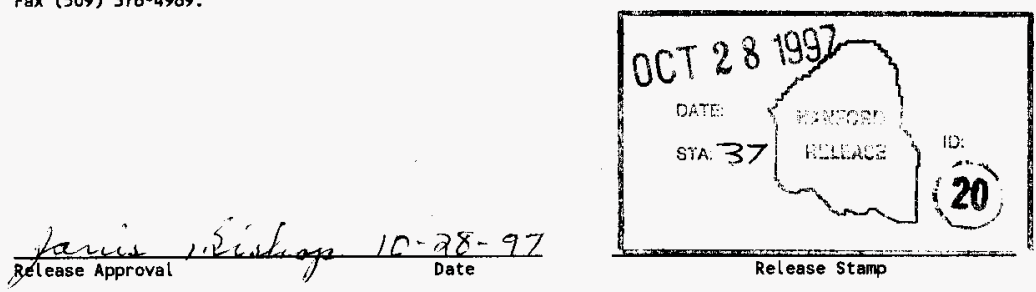


\title{
HANFORD TANKS INITIATIVE RISK MANAGEMENT GUIDE
}

October 1997

\author{
P. S. Schaus \\ Lockheed Martin Hanford Corporation \\ Richland, Washington \\ J. C. Schaefer \\ TRW \\ Richland, Washington
}

Prepared for

U.S. Department of Energy

Richland, Washington 
HNF-1739

Revision 0

This page intentionally left blank. 
HNF-1739

Revision 0

\section{CONTENTS}

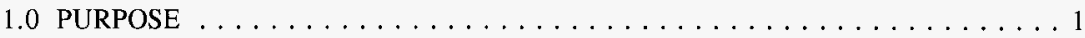

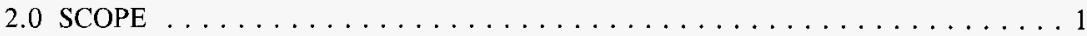

3.0 DEFINITIONS AND ACRONYMS $\ldots \ldots \ldots \ldots \ldots \ldots \ldots \ldots \ldots \ldots \ldots \ldots$

4.0 RISK MANAGEMENT PROCESS $\ldots \ldots \ldots \ldots \ldots \ldots \ldots \ldots \ldots \ldots$

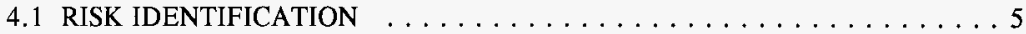

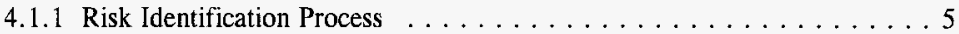

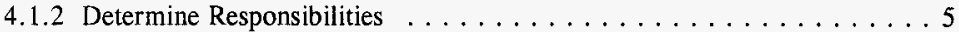

4.2.1 Determine Risk Likelihood . . . . . . . . . . . . . . . . 7

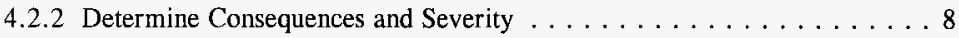

4.2.3 Determine if Risk Is Critical to the Success of the Hanford Tanks Initiative

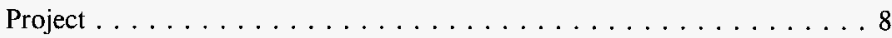

4.2.4 Document Risk Information . . . . . . . . . . . . . . . 9

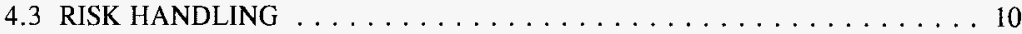

4.3.1 Develop Risk Actions $\ldots \ldots \ldots \ldots \ldots \ldots \ldots \ldots \ldots$

4.3.2 Document Risk Action . . . . . . . . . . . . . . . 11

4.3.3 Prioritize Risk Actions . . . . . . . . . . . . . . . 11

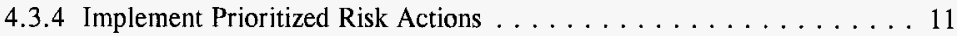

4.4 RISK MONITORING $\ldots \ldots \ldots \ldots \ldots \ldots \ldots \ldots \ldots \ldots \ldots$

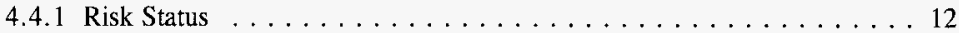

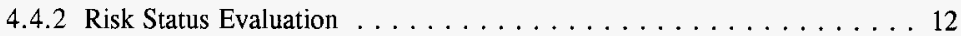

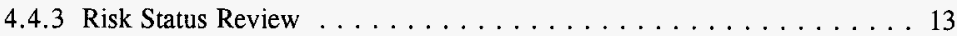

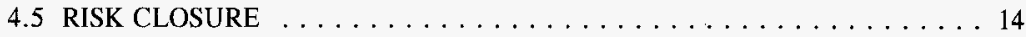

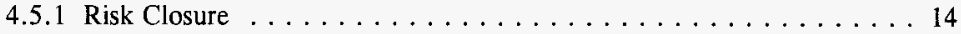

4.5.2 Record Closure Information $\ldots \ldots \ldots \ldots \ldots \ldots \ldots \ldots \ldots$

4.5.3 Disseminate Closure Notice . . . . . . . . . . . . . . . . . 14

5.0 RISK MANAGEMENT DOCUMENTATION AND

ADMINISTRATIVE ISSUES $\ldots \ldots \ldots \ldots \ldots \ldots \ldots \ldots \ldots \ldots$

5.1 PROGRAMMATIC RISK INFORMATION MANAGEMENT SYSTEM . . . . 15

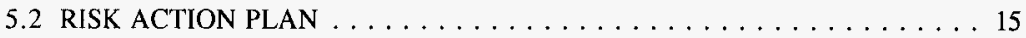

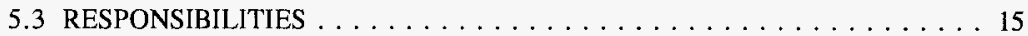

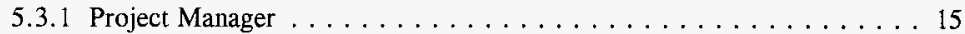

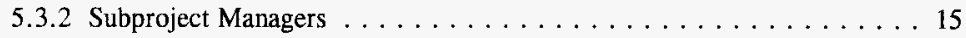

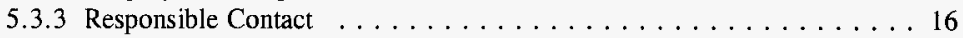

5.3.4 Hanford Tanks Initiative Team . . . . . . . . . . . . . . 16

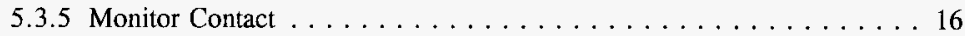

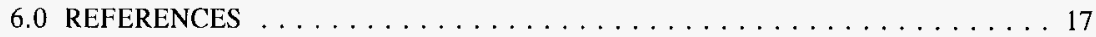

7.0 ATTACHMENTS (AS REQUIRED) $\ldots \ldots \ldots \ldots \ldots \ldots \ldots \ldots$ 
HNF-1739

Revision 0

\section{FIGURES}

1. Hanford Tanks Initiative Risk Management Process Overview . . . . . . . . . . 4

\section{TABLES}

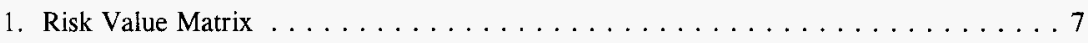

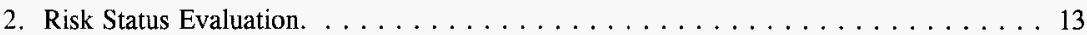


HNF-1739

Revision 0

\section{HANFORD TANKS INITIATIVE RISK MANAGEMENT GUIDE}

\subsection{PURPOSE}

The purpose of this document is to provide guidance and direction for performing risk management for the Hanford Tanks Initiative (HTI) project. The guide has been written to encourage flexibility during implementation, while still providing a consistent basis for approaching risk management. The information and processes within this guide were adapted from the Tank Waste Remediation System (TWRS) Risk Management Procedure (PHMC 1997b).

\subsection{SCOPE}

Risk is defined as the combination of the probability of an unwanted event occurring and the consequences if the event does occur. A "risk" is not a "problem." Simply, a problem is a risk that has occurred, and therefore requires problem management. Risk management consists of the steps taken to identify, assess, analyze, handle, monitor, and close-out risks. The use of this procedure by the HTI Project is intended to address programmatic cost and schedule risks, technical risks, and impacts of Environmental, Safety, and Health (ES\&H) requirements. A specific Risk Management Plan will not be generated for HTI. If necessary, references may be made to the TWRS Programmatic Risk Management Plan (Awadalla 1996). In the event of a conflict between this document and any other risk management plan or procedure, this document will take precedence.

Just as at the TWRS level, the HTI risk management approach will include interactions with the Alternative Generation and Analysis (AGA), the HTI Decision Management Process (PNNL 1997), and the TWRS Administration, "TWRS Decision Management Procedure" (PHMC 1997d). As risks are handled through action plans and status updates, they may drive the need for further decisions and trade studies. 
HNF-1739

Revision 0

This page intentionally left blank. 
HNF-1739

Revision 0

\subsection{DEFINITIONS AND ACRONYMS}

A-Risk List

AGA

HTI

HTI team

Monitor Contact

PRIMS

Responsible Contact

Risk

RL

RMP

TWRS
The informal, HTI record of acceptable, Low/Very Low risks, and alternative Action Plans

Alternative Generation and Analysis

Hanford Tanks Initiative

The group of HTI personnel involved in risk management

A person from another TWRS project who needs to be kept informed of the status of a risk because it has a potential impact on their project.

Programmatic Risk Information Management System, a risk database

\subsection{RISK MANAGEMENT PROCESS}

The steps identified below define the process used to satisfactorily and proactively manage risk. It is recommended that all of the steps be performed. However, the extent and formality of each step will vary with the unwanted event identified, potential consequence(s), and the other qualitative factors that influence risk management. See Figure 1 for a process overview of the HTI Risk Management Process. 
HNF-1739

Revision 0

Figure 1. Hanford Tanks Initiative Risk Management Process Overview.
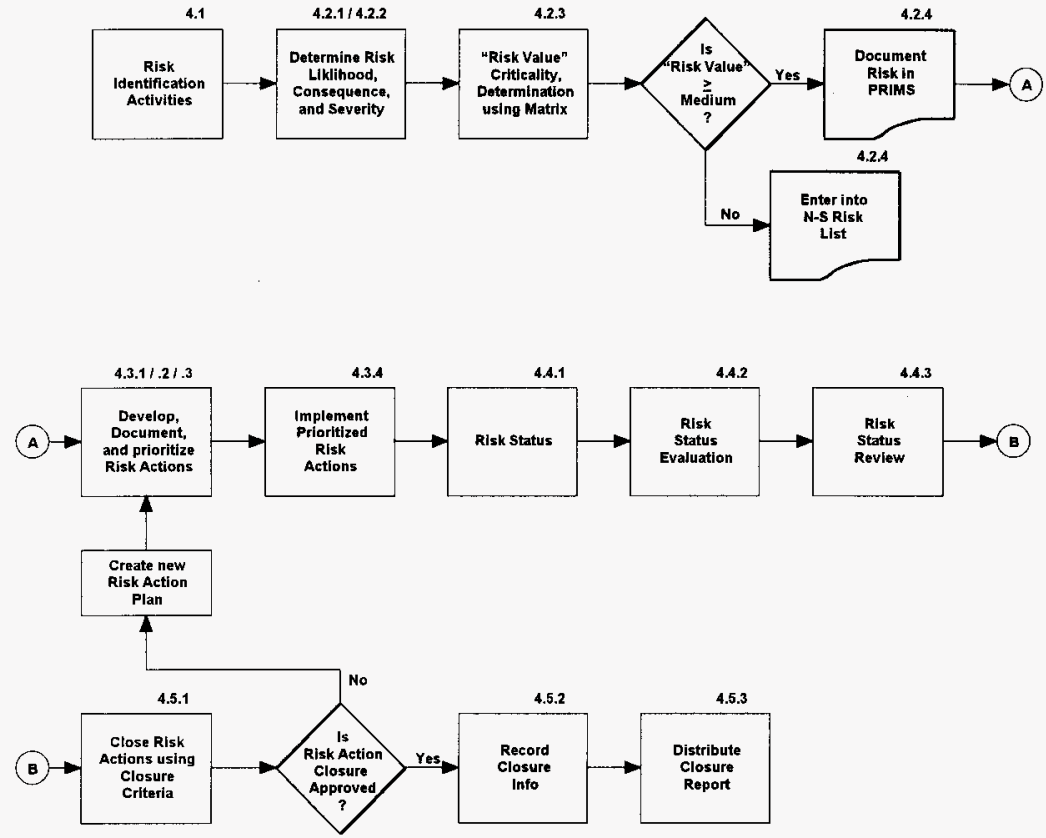

PRIMS = Programmatic Risk Information Management System. 
HNF-1739

Revision 0

\subsection{RISK IDENTIFICATION}

The task of identifying risks is a multi-step and iterative process that begins with the identification of possible unwanted events and ends with development of risk information that are documented in the PRIMS (Programmatic Risk Information Management System) database or the HTI A-Risk list. The TWRS Risk Management Procedure (Awadalla 1996) prescribes the use of PRIMS for recording project risk information.

The prime source for technical performance risks are trade studies performed as part of the AGA process. Other sources for technical performance risks are the HTI and TWRS Mission Analysis Report and the H'TI Functions and Requirements. These sources include the issues and system functional and process flow diagrams that accompany functions and requirements documents. Additional sources for technical performance risks are the tracking and reporting activities performed during Technical Performance Measurement. The Technical Performance Measurement procedure describes how technical performance measures are to be managed and used to provide input to risk management and decision management.

The prime source for cost and schedule risks will be the Multi-Year Program Plan and the Work Breakdown Structure. Other sources for cost and schedule risks are Data Quality Objectives, project reviews, and meetings.

To simplify the references to the group of HTI personnel involved in risk management, the term "HTI team" will be used. For HTI, a Responsible Contact, the person most familiar with the risk, will be assigned for each risk identified.

\subsubsection{Risk Identification Process}

a. The HTI team will meet at least bi-monthly to identify risks using the sources mentioned in paragraph 4.1 .

b. Initially, the HTI team will meet at least weekly in a set of meetings to focus on identifying risks.

\subsubsection{Determine Responsibilities}

a. The Project Manager will assign each risk to a Responsible Contact (see Section 5.3 for full set of responsibilities).

b. Identifying a Monitor Contact is optional, depending on the need to share risk information across organizations (see Section 5.3 for definition). 
HNF-1739

Revision 0

\subsection{RISK ASSESSMENT AND ANALYSIS}

The objective of risk assessment and analysis is to accomplish the following:

1. Determine risk likelihood.

2. Determine consequences, including identifying affected HTI functions.

3. Determine consequence severity.

4. Determine if risk is critical to the success of the HTI Project / TWRS Project.

The following paragraphs provide a definition to the above four objectives. Starting with subsection 4.2.1 are the procedure steps to achieve the objectives.

Risk likelihood is the probability that an unwanted event will occur if no further action is taken to prevent it from happening. The method used to determine the probability of occurrence may be qualitative or quantitative. By "qualitative" it is meant that subjective judgment may be used for risk probabilities, whereas, "quantitative" means that a risk likelihood has numerical data to backup the probability. Whichever method is chosen, it must be consistently applied and recorded. To standardize the ratings for risk likelihood, a qualitative rating scheme of low, medium, or high will be used (see 4.2 .1 below) in this procedure.

Consequences are the negative effects of an unwanted event occurring. Consequences can be determined by building possible project event scenarios or by using a more formal analysis approach, such as described in the Decision and Risk Analysis training to TWRS and HTI in June 1997. A part of preparing a list of consequences is to determine the impacted HTI system functions. HTI functions and requirements documents, other technical documentation, and outputs from process simulation models are all sources for identifying affected functions.

Consequence severity is the magnitude of the negative effect of a unwanted event on cost, schedule, and technical performance. The sources used to identify unwanted events, consequences, and affected functions should also be used to determine consequence severity. To standardize the ratings for consequence severity, a qualitative rating scheme of low, medium, or high will also be used in the procedure (see 4.2 .2 below).

Critical risks are the risks that require the most management and technical staff attention. The designation "Critical" is a subjective indicator of the need to intensively manage a risk based on its programmatic impact. (Note: Most Critical Risks will be added to the TWRS Risk Management List. In general, HTI risks that are selected to be integrated into the TWRS level are ones that require handling procedures beyond the ability of the HTI project or are Critical to the completion of the project.) Risk Value is a means to rate the overall importance of risk based on the relationship between Risk Likelihood and Consequence Severity. Risk 
HNF-1739

Revision 0

Value is a magnitude guideline and an interpretive measure of programmatic impact. To standardize the Risk Value rating process, a qualitative Risk Value Matrix (see Table 1) is to be used. To supplement the Risk Value Matrix, subjective criteria were developed to aid in making a decision about designating a risk as Critical or Not Critical, because Risk Value may not be the sole adequate discriminator. Whether a risk is Critical or Not Critical will influence the amount of effort that should be put in risk action planning (see Section 4.3).

Table 1. Risk Value Matrix.

\begin{tabular}{|c|c|c|c|}
\hline \multirow{2}{*}{ Risk likelihood } & \multicolumn{3}{|c|}{ Consequence Severity } \\
\cline { 2 - 4 } & Low & Medium & High \\
\hline Low & Very low & Low & Medium \\
\hline Medium & Low & Medium & High \\
\hline High & Medium & High & Very high \\
\hline
\end{tabular}

\subsubsection{Determine Risk Likelihood}

a. The HTI team will jointly determine the likelihood of a risk occurring.

b. Individual HTI team members will assign a probability of occurrence using a value between 0 and 1 ( 0 equates to no probability of occurrence and 1 equates to 100 percent probability of occurrence).

c. The HTI team will decide on one probability from among all the estimates. Note, a subjective method may be used to assign one probability. This is to allow the HTI team members to apply group knowledge and not be bound by a mathematical computation.

d. The Responsible Contact will assign a qualitative rating for the risk using the following guidelines:

- Low--Risk likelihood is less than 25 percent $(<0.25)$.

- Medium--Risk likelihood is from 25 percent to 75 percent $(0.25$ to 0.75$)$.

- High--Risk likelihood is greater than 75 percent $(>0.75)$. 
HNF-1739

Revision 0

\subsubsection{Determine Consequences and Severity}

a. The HTI team will determine the impact to cost and schedule and will determine all of the affected HTI functions.

b. The HTI team will use the list of sources described in 4.1 to identify possible consequences and determine the severity of each consequence. The consequences will then be analyzed for their impact on the HTI Project (e.g., duration, intensity, and degree of disruption).

c. The HTI team will use a qualitative rating scheme of low, medium, or high. The qualitative ratings are to be selected using the following guidelines:

- Low--Has minor impact on system functions, or requires minor changes to cost and schedule goals and technical performance measurements (e.g., minor changes within the scope of a project's own budget). For the HTI Project $\$ 100,000$ or less has been set for the value of a low severity consequence.

- Medium--Has significant impact on system functions, or requires significant changes to cost and schedule goals and technical performance measurements (e.g., reprogram project to get funding from some other project within the program). An impact of over $\$ 100,000$ but less than $\$ 500,000$ has been set for the value of a medium severity consequence. A consequence with a medium severity rating may require more analysis to clarify its potential impact.

- High--Has critical impact on system functions, or requires critical changes to cost and schedule goals and technical performance measurements (e.g., project goes back to DOE for additional funding). For the HTI Project $\$ 500,000$ or more has been set for the value of a high severity consequence.

\subsubsection{Determine if Risk Is Critical to the Success of the Hanford Tanks Initiative Project}

a. The HTI team will determine the risk value using the qualitative Risk Value Matrix shown in Figure 2. The following are the definitions of the Risk Value Matrix relationships:

- Very Low--Risk likelihood is low and consequence severity is low.

- Low--Risk likelihood is low and consequence severity is medium, or risk likelihood is medium and consequence severity is low. 
HNF-1739

Revision 0

- Medium--Risk likelihood is low and consequence severity is high, risk likelihood is medium and consequence severity is medium, or risk likelihood is high and consequence severity is low.

- High--Risk likelihood is medium and consequence severity is high, or risk likelihood is high and consequence severity is medium.

- Very High--Risk likelihood is high and consequence severity is high. Risks with a risk value of Very High will be designated as Critical. Risk determined to have a risk value of Medium or High should be designated as Not Critical unless a qualitative assessment using the criteria described in item $b$, below, determines a Critical risk designation is required. Risks determined to have a Risk Value of Very Low or Low will be designated as acceptable, and these risks will be managed in a separate list for future reference (the A-Risk List).

b. Additionally, a risk may be designated as Critical with a risk value of less than Very High if one or more of the following subjective criteria apply:

- Consequence severity is particularly serious.

- Immediate action is required to preclude the unwanted event from happening.

- Avoiding the risk is a top stakeholder priority, or a top priority of TWRS or RL.

- Completion of a PHMC performance agreement (PA) is potentially impacted by the risk.

- $\quad$ Risk handling will be very difficult to coordinate with other parties.

- Senior management oversight is required (i.e., the risk is selected to be integrated into the TWRS Risk Management List).

\subsubsection{Document Risk Information}

a. For risk values of Medium, High, and Very High, the Responsible Contact will ensure the following are entered into PRIMS: the Likelihood rating; the severity rating, consequences, and the source(s) used to determine the severity rating; and the risk value and the source(s) used to determine the risk value, including whether a tool other than the Risk Value Matrix was used. Also entered into PRIMS will be the details of where and how the ratings were assigned.

b. For risk values of Low and Very Low, the Responsible Contact will ensure the 
HNF-1739

Revision 0

following are recorded in the A-Risk List: the Likelihood rating; the severity rating, consequences, and the source(s) used to determine the severity rating; and the risk value and the source(s) used to determine the risk value, including whether a tool other than the Risk Value Matrix was used. Also entered will be the details of where and how the ratings were assigned. These will be retained for future consideration. Refer to Attachment A for an outline on documenting the information for the informal HTI list.

\subsection{RISK HANDLING}

The objective of risk handling is to develop actions that are realistic and achieve the goal of reducing (1) the unwanted event's probability of occurrence and/or (2) the consequence of occurrence to an acceptable level. It is not necessary to prepare a formal action plan for each risk; however, formal action plans are recommended for Critical risks. More abbreviated and less formal plans are recommended for Non Critical risks. Risk handling requires continuous management attention. Some risk actions may address more than one risk and as such must be carefully coordinated. Actions that cross organizational boundaries will require the coordination from affected programs and projects. It is also possible that some risk handling actions may compound problems for other organizations, and in turn generating a new set of risks. Therefore, the HTI manager and technical staff should pay particular attention to this possibility when involved in Risk Management activities.

\subsubsection{Develop Risk Actions}

a. The HTI team will determine the best technique for reducing risk to an acceptable level using:

- Avoidance--Action taken to completely rule out the potential for an unwanted event and its consequences by choosing a different approach or solution.

- Transfer--Action taken to entirely give a risk to another organization through contractual agreement (e.g., privatization), or arrangement.

- Sharing--Action taken to allocate a portion of a risk to another organization so as to reduce risk likelihood or consequence severity.

- Control--Action taken to monitor and correct conditions so that either risk likelihood or consequence severity, or both, are reduced.

- Assumption--Decision made to accept a risk should it occur and to take no action beforehand. 
HNF-1739

Revision 0

b. The HTI team will evaluate each Risk Action from a cost-benefit perspective as described in Potential Enhancements to Addressing Programmatic Risk in the Tank Waste Remediation System (PNNL 1996).

c. The Responsible Contact will control and document in the HTI A-Risk List, for future consideration, those alternative Risk Actions not immediately adopted by the HTI team.

d. The Responsible Contact will ensure entry into PRIMS of the selected Risk Actions.

\subsubsection{Document Risk Action}

If it is deemed necessary, the Responsible Contact will prepare a Risk Action Plan. Each Risk Action Plan will state the technique (i.e., avoid, transfer, share, control, assume) and the criteria for closing the Risk Action Plan, as well as the Cost and Schedule impacts for all Critical Risks.

\subsubsection{Prioritize Risk Actions}

a. The Project Manager will ensure that an unique identification number is assigned to each Risk Action (a risk could have more than one action).

b. The HTI team will prioritize each action. Priorities will take into account the greatest risk handling potential for the resources expended.

\subsubsection{Implement Prioritized Risk Actions}

After obtaining approval of the prioritized list by the project manager, the HTI team will implement the risk handling actions.

\subsection{RISK MONITORING}

Risk Monitoring provides a continuous status of each risk and its associated Risk Action Plan. An essential aspect of risk monitoring is to evaluate the status of each risk action, whether Pending, Ongoing, or Complete. This evaluation is a subjective assessment of how well the risk is being handled, and not how serious the risk is to HTI. For example, risk status ratings may need updating based on the duration of the HTI Project, as well as system performance. Also, there may be a need to revisit and reevaluate any "acceptable risks" (in the A-Risk List) to determine if circumstances have elevated their importance. The purpose of risk reviews is to determine whether risk handling actions are on track or need to be altered. 
HNF-1739

Revision 0

These reviews should be proactive and conducted to allow sufficient time for corrective action, and not crisis oriented. At a minimum, risk reviews should be tied to program/project milestone reviews and verification activities (e.g., test and evaluation). One risk status tool is the System Effectiveness and Summary Status Report described in the TWRS Technical Performance Measurement Procedure (PHMC 1997a). The status report is a record of achieved performance profiles and summarizes the key findings of technical performance measurement. The status report should be used as an input to determining overall risk status and the status of risk actions.

\subsubsection{Risk Status}

a. The Responsible Contact will report the status of each Risk Action to the HTI team using the following status items.

- Pending--Action has not yet started, or a decision has not yet been made to adopt the action.

- Ongoing--Action started, but is not yet complete.

- Complete--Action fully implemented.

b. The HTI team will review monthly the risk status and any needed changes in Risk Action Plans.

c. The Responsible Contact will record the any HTI team status decisions into PRIMS.

\subsubsection{Risk Status Evaluation}

a. The Responsible Contact will evaluate the overall status of each risk and assign a category color. The results will be entered into PRIMS by the Responsible Contact. The following are the definitions of each category:

- Green--Risk handling is expected to reduce risk to an acceptable level and is on schedule and within budget.

- Amber--Mitigation actions may fall short of reducing risk to an acceptable level and minor deviation exists between planned risk handling and schedule and budget.

- Red--Mitigation actions are expected to fall far short of reducing risk to an acceptable level and major deviation exists between risk handling and schedule and budget. Management intervention is required. 
HNF-1739

Revision 0

b. The Responsible Contact will review risks in accordance with Table 2 .

Table 2. Risk Status Evaluation.

\begin{tabular}{|c|c|c|}
\hline Status evaluation & Minimum frequency & Maximum frequency \\
\hline Red & Every two weeks & Every day \\
\hline Amber & Every month & Every week \\
\hline Green & Every three months & Every month \\
\hline
\end{tabular}

\subsubsection{Risk Status Review}

\subsubsection{Subproject Review.}

a. At least once every six months (preferably quarterly), the Subproject Manager will review all Subproject risks.

b. Existing risks will be reviewed for changes in the Risk Likelihood and Severity.

c. Existing risks designated as Critical that have had a decrease in either Likelihood or Severity will be presented to the HTI Project Manager, including a justification for the "downgrade" (removal of the Critical designation).

d. New risks, and existing risks that have had an increase in Likelihood or Severity, will be presented to the Project Manager for possible "upgrade" (assignment of the Critical designation).

\subsubsection{Hanford Tanks Initiative Project Review.}

a. At least once every six months (preferably quarterly), the Project Manager will review new risks and the Critical risks.

b. Existing Critical risks will be reviewed for changes that would either "downgrade" or "upgrade" the risk.

c. Risks "downgraded" will be referred back to the appropriate Subproject Manager.

d. New risks, and risks "upgraded" by the Subprojects, will be reviewed by the Project Manager and, if necessary, designated as Critical to allow the Project Manger the ability to more closely monitor the risk(s). 
HNF-1739

Revision 0

\subsection{RISK CLOSURE}

Closure is the point in time when the unwanted event is at the acceptable consequence level or no longer an issue for HTI. Risk Closure steps are: (1) close the risk, (2) record the information in PRIMS, and (3) disseminate the closure notice to the HTI and TWRS community. Communication to the HTI Project and TWRS program is important because Risk Action closure may mean a new Risk Action Plan is needed due to consequences from managing the previous Risk.

\subsubsection{Risk Closure}

a. The Responsible Contact will inform the HTI team of closure by using the status report (from 4.4.1 above) to report Completed Actions.

b. The HTI team will review the closure information and determine disposition, which may include the possible creation of a new Risk Action Plan. The HTI team will use the criteria in the Risk Action Plan to determine closure of the Action Plan.

\subsubsection{Record Closure Information}

a. The Responsible Contact will update all of the specific Risk information in the PRIMS database.

b. The Responsible Contact will provide a signed copy of the closed Risk Action Plan to the Project Manager.

\subsubsection{Disseminate Closure Notice}

The Project Manager will distribute the closure report to the HTI and TWRS community. 
HNF-1739

Revision 0

\subsection{RISK MANAGEMENT DOCUMENTATION AND ADMINISTRATIVE ISSUES}

\subsection{PROGRAMMATIC RISK INFORMATION MANAGEMENT SYSTEM}

The Programmatic Risk Information Management System (PRIMS) has been developed to record and manage information. The database application has features that provide for tracking historical risk data, maintaining a risk management list, and recording qualitative and numerical likelihood and severity data that can be used during Risk Management activities. In the TWRS Risk Management Procedure (PHMC 1997b), Attachments A and D contain a description of PRIMS and its major data tables, and a Glossary of the terms, respectively. The HTI Project will use PRIMS to create and manage the HTI Risk List.

\subsection{RISK ACTION PLAN}

The Risk Action Plan is the means by which the Responsible Contact documents a risk and its handling (mitigation). Attachment $\mathrm{C}$ of the TWRS Risk Management Procedure (PHMC 1997b) provides an annotated outline for a Risk Action Plan. Section 5 of a Risk Action Plan should include the criteria for removing or closing a risk.

\subsection{RESPONSIBILITIES}

The following subparagraphs identify specific duties for HTI personnel in order to provide the best possible Risk Management. The exception is the subparagraph on Monitor Contact, is not a member of the HTI personnel.

\subsubsection{Project Manager}

The Project Manager (PM) will be the responsible party for overseeing all of the HTI Project risk management and decision making. In this role, he will be responsible for ensuring that risks outside of his HTI Project control are reported to the Waste Disposal Division Critical Risk Management List. The PM will ensure HTI Project risks are reported to the TWRS level for possible inclusion on the Technical Issues Management List. The PM will be responsible for coordinating risk management with other projects and at the site level.

\subsubsection{Subproject Managers}

The Subproject Managers are responsible for identifying unwanted events and consequences, writing the Risk Action Plans, and monitoring the Action Plans for completion of risk handling. These Managers will be responsible for reporting risk management issues at 
HNF-1739

Revision 0

the Subproject Managers meeting each week.

\subsubsection{Responsible Contact}

The Responsible Contact will enter risks accepted as being significant into PRIMS, will track risks actions not immediately adopted, will track the different risk action options, will develop the Risk Action Plan, and will review and status the risks periodically based on the risk value.

\subsubsection{Hanford Tanks Initiative Team}

The remaining HTI organization personnel are responsible for assisting the subproject managers in identifying risks and working the plans.

\subsubsection{Monitor Contact}

The person from another project who needs to be kept informed of the status of the risk because it has a potential impact on their project is referred to as the Monitor Contact. 
HNF-1739

Revision 0

\subsection{REFERENCES}

Awadalla, N. G., 1996, TWRS Programmatic Risk Management Plan, WHC-SD-WM-PMP-018, Rev. 1, Westinghouse Hanford Company, Richland, Washington.

PHMC, 1997a, TWRS Administration, "TWRS Technical Performance Measurement Procedure," HNF-IP-0842, Vol. IV, Section 2.4, Project Hanford Management Contractor, Fluor Daniel Hanford, Richland, Washington.

PHMC, 1997b, TWRS Administration, "TWRS Risk Management Procedure," HNF-IP-0842, Vol. IV, Section 2.6., Project Hanford Management Contractor, Fluor Daniel Hanford, Richland, Washington.

PHMC, 1997c, TWRS Administration, "TWRS Alternative Generation and Analysis Procedure," HNF-IP-0842, Vol. IV, Section 3.3., Project Hanford Management Contractor, Fluor Daniel Hanford, Richland, Washington.

PHMC, 1997d, TWRS Administration, "TWRS Decision Management Procedure," HNF-IP-0842, Vol. IV, Section 2.7., Project Hanford Management Contractor, Fluor Daniel Hanford, Richland, Washington.

PNNL, 1996, Potential Enhancements to Addressing Programmatic Risk in the Tank Waste Remediation System (TWRS) Program, PNNL-11068, Pacific Northwest National Laboratory, Richland, Washington.

PNNL, 1997, HTI Decision Management Process, (June 26), Pacific Northwest National Laboratory, Richland, Washington. 
HNF-1739

Revision 0

This page intentionally left blank. 
HNF-1739

Revision 0

\subsection{ATTACHMENTS (AS REQUIRED)}

Note, the TWRS Risk Management Procedure (PHMC 1997b) and its attachments provide detailed information.

\section{ATTACHMENT A}

\section{OUTLINE FOR ACCEPTABLE RISK DOCUMENTATION}

1. Title: < Provide a title for the Risk. >

2. Risk Description: <Provide a short description of the Risk. >

3. Point-of-Contact: < Provide the name of the HTI person with knowledge about this risk and the analysis. $>$

4. Analysis Description: < Provide a description of the risk analysis and HTI team discussion that made the determination the risk is acceptable, but will not be addressed at this time and/or provide a short description of the risk likelihood analysis that led to the determination the consequences are not significant. $>$ 
HNF-1739

Revision 0

This page intentionally left blank. 


\section{DISTRIBUTION SHEET}

\begin{tabular}{|c|c|c|c|c|c|}
\hline \multirow{2}{*}{$\begin{array}{l}\text { To } \\
\text { DISTRIBUTION }\end{array}$} & \multirow{2}{*}{\multicolumn{3}{|c|}{$\begin{array}{l}\text { From } \\
\text { PS Schaus }\end{array}$}} & \multicolumn{2}{|l|}{ Page 1 of 1} \\
\hline & & & & \multicolumn{2}{|c|}{ Date $10 / 27 / 97$} \\
\hline \multicolumn{4}{|l|}{ Project Title/Work Order } & \multicolumn{2}{|c|}{ EDT No. 622809} \\
\hline \multicolumn{4}{|c|}{ Hanford Tanks Initiative Risk Management Guide, HNF-1739, Rev. 0} & \multicolumn{2}{|l|}{ ECN No. } \\
\hline Name & MSIN & $\begin{array}{l}\text { Text } \\
\text { With All } \\
\text { Attach. }\end{array}$ & Text Only & $\begin{array}{l}\text { Attach./ } \\
\text { Appendix } \\
\text { Only }\end{array}$ & $\begin{array}{l}\text { EDT/ECN } \\
\text { Only }\end{array}$ \\
\hline $\begin{array}{l}\text { CENTRAL FILES } \\
\text { HTI PROJECT FILES (2) }\end{array}$ & $\begin{array}{l}\mathrm{Bl}-07 \\
\mathrm{H} 6-08\end{array}$ & $\begin{array}{l}x \\
x\end{array}$ & & & \\
\hline
\end{tabular}

\section{DESH}

JW B 7 oom

H6-12

$x$

FLUOR DANIEL NORTHWEST

JJ Huston

FLUOR DANIEL HANFORD, INC.

DJ Washenfelder

INFORMATICS CORPORATION

B Root

LOCKHEED MARTIN HANFORD CORPORATION

KE McKinney
RJ Murkowski
SM $0^{+}$Toole
LG Peck
PS Schaus

NUMATEC HANFORD CORPORATION

DL Becker

PW Gibbons

LB McDaniel

PACIFIC NORTHWEST NATIONAL LABORATORY
H5-61 $\quad X$

S7 $-40 \quad X$

H6-12 $\quad X$
H5-03

H6-37

G3-21

$\mathrm{H} 6-35$

H5-03 $x$

$x$

$x$

$x$

$x$

$x$

$x$

H6-12 X

H6-12 $X$

H6-12 $X$

$\begin{array}{ll}K 9-91 & X \\ K 9-46 & X \\ K 8-07 & X\end{array}$

K8-50 $X$

K8-50 $\mathrm{X}$

S7-53 X

RL/DOE

JP Hanson

CD West 